\title{
Exploring Emotional Intelligence Among Master's-Level Counseling Trainees
}

Daniel Gutierrez

William \& Mary, dgutierrez@wm.edu

Patrick R. Mullen

William \& Mary, prmullen@wm.edu

Jesse Fox

Follow this and additional works at: https://scholarworks.wm.edu/aspubs

\section{Recommended Citation}

Gutierrez, Daniel; Mullen, Patrick R.; and Fox, Jesse, Exploring Emotional Intelligence Among Master'sLevel Counseling Trainees (2017). Counselor Education and Supervision, 56(1), 19-32.

https://doi.org/10.1002/ceas.12057

This Article is brought to you for free and open access by the Arts and Sciences at W\&M ScholarWorks. It has been accepted for inclusion in Arts \& Sciences Articles by an authorized administrator of W\&M ScholarWorks. For more information, please contact scholarworks@wm.edu. 


\title{
Exploring Emotional Intelligence Among Master's-Level Counseling Trainees
}

\author{
Daniel Gutierrez, Patrick R. Mullen, and Jesse Fox
}

\begin{abstract}
The authors explored the relationship between counseling trainees' emotional intelligence (EI), empathy, stress, distress, and demographics. Results indicated that higher levels of EI were associated with lower stress and distress, higher affective and cognitive empathy, and age. These findings suggest curricular integration of EI and potential utility of EI measures to evaluate students' progress throughout the program.
\end{abstract}

Keywords: emotional intelligence, empathy, stress, distress, counselor development

Counselors create professional therapeutic relationships that serve to empower clients, but this work can be emotionally demanding (Bakker, Van Der Zee, Lewig, \& Dollard, 2006; Kaplan, Tarvydas, \& Gladding, 2014; Skovholt, Grier, \& Hanson, 2001). Hence, the nature of counseling can quickly lead to emotional exhaustion (Lee et al., 2007; Young \& Lambie, 2007), which is partially due to the need for counselors to remain empathic (Stebnicki, 2007). Stebnicki (2007) called this empathy fatigue and cautioned that this experience could affect personal growth, professional development, and overall well-being. Thus, counselor educators and supervisors have a responsibility to support and help counselors-in-training cope with emotional fatigue and avoid exhaustion and burnout (Roach \& Young, 2007). Previous research has demonstrated that emotional intelligence (EI) is associated with counselor distress (Gutierrez, Conley, \& Young, 2016; Gutierrez \& Mullen, 2016).

EI refers to the dispositions and cognitive capacity associated with how one manages, understands, and uses emotions (Mayer, Salovey, \& Caruso, 2008; Petrides \& Furnham, 2001). Young (2013) remarked that there is little doubt that counselors require EI. Specifically, EI relates to fundamental clinical counseling skills, such as reflecting feeling and building interpersonal relationships (Goleman, 2005; Ivey, Ivey, \& Zalaquett, 2013; Young, 2013). Recently, research has demonstrated that a counselor's EI also relates to self-care (Gutierrez et al., 2016; Gutierrez \& Mullen, 2016). In addition, we located two studies that assessed the influence of EI with counselor trainees (e.g., Easton, Martin, \& Wilson, 2008; Martin, Easton, Wilson, Takemoto, \& Sullivan, 2004). These results showed that counselor trainees demonstrated higher scores on the Emotional Judgment Inventory (EJI; Bedwell, 2002)

\footnotetext{
Daniel Gutierrez, Department of Counseling, University of North Carolina at Charlotte; Patrick R. Mullen, Department of School Psychology and Counselor Education, College of William and Mary; Jesse Fox, Pastoral Counseling Department, Loyola University Maryland. Correspondence concerning this article should be addressed to Daniel Gutierrez, Department of Counseling, University of North Carolina at Charlotte, 9201 University City Boulevard, Charlotte, NC 28223 (e-mail: dgutierrez@uncc.edu).
} 
compared with the general population, EI had a statistically significant relationship with counselor self-efficacy, and counselor self-efficacy predicted EJI scores (Easton et al., 2008; Martin et al., 2004).

Therefore, it is plausible that EI could serve an important function in counselor development. The initial research by Martin and colleagues (2004) demonstrated that EI is a characteristic of being a counselor, but little is known about how EI contributes to other components of counseling, such as empathy. Empathy is a complex and multidimensional construct that describes one's ability to understand and connect with the cognitive and emotional experiences of a client (Davis, 1980; Elliott, Bohart, Watson, \& Greenberg, 2011). Davis (1980) described empathy as including two interdependent types: (a) cognitive empathy, or the ability to understand a client's frame of reference and take on his or her perspective, and (b) affective empathy, which is the degree an individual feels warmth and concern for another. Rogers (1957) likened empathy to entering into the client's phenomenological experience of the world and stated that empathy was a necessary condition for psychological change. Rogers declared "to sense the client's private world as if it were your own, but without ever losing the 'as if' quality-this is empathy, and this seems essential to therapy" (p. 99). Empathy has been a key concept in understanding why and how counseling works (Duan \& Hill, 1996; Rogers, 1957). The results of a meta-analysis indicated that empathy was a strong predictor of outcomes (Elliott et al., 2011; Norcross, 2011). Moreover, researchers who investigated the top factors associated with effective psychotherapy ranked empathy as one of the most essential counselor skills (Bike, Norcross, \& Schatz, 2009; Norcross \& Wampold, 2011).

The relationship between empathy and EI has never been clear. Mayer et al. (2008), who are credited with providing the scientific understanding of EI, described empathy as a distinct construct. However, Goleman (2005), who popularized the concept of EI, and Bar-On (1997) believed that EI and empathy are related. Petrides and Furnham (2001, 2003), who created the scale used in this study, suggested that trait empathy, the dispositional tendency to show understanding and concern for another's viewpoint and emotional needs, is a related construct, but they did not provide evidence to further describe this relationship. Therefore, research that investigates the relationship between trait EI and the various types of empathy (i.e., cognitive and affective empathy) is needed. Likewise, emerging research (Gutierrez \& Mullen, 2016) has also indicated that EI could serve as a buffer to burnout, but this research is in its infancy and has not been examined with student counselors. Further research is also needed to expand the relationships between EI and stress in counselors and to ascertain how it influences the core characteristics of counselors, such as empathy. Finally, little is known about the relationship between EI and counseling trainees' demographic characteristics (e.g., age, gender, time in degree program). A deeper understanding of the demographic profiles of student counselors affected by EI could provide a more nuanced understanding of its influence.

Counseling trainees can experience overwhelming feelings of anxiety and stress (Stoltenberg \& McNeill, 2010), which often impedes their performance 
(Bowman, Roberts, \& Giesen, 1978; Friedlander, Keller, Peca-Baker, \& Olk, 1986; Stoltenberg \& McNeill, 2010; Young, 2013) and has a negative influence on their levels of empathy (Bowman \& Giesen, 1982). Given the intimate and emotional nature of counseling, counselors are susceptible to empathy fatigue, countertransference, and burnout (Hayes \& Gelso, 2001; Stebnicki, 2007). We hypothesized that counselors with high EI are able to self-manage or regulate emotions and reduce the influence of anxiety and stress, while using their understanding of these emotions to inform their behaviors (Salovey \& Mayer, 1990). Moreover, individuals with high EI may be skilled in identifying emotions in others, self-aware of their emotional states, and able to manage their relationships (Cherniss \& Goleman, 2001; Goleman, 2005). In essence, EI requires empathy (i.e., the ability to be sensitive to and correctly identify another's feelings; Goleman, 2005).

Effective counselors manage stress and possess and maintain empathy toward others. Therefore, understanding counseling trainees' EI, as well as its relationship to stress, could be important to counselor educators. A better understanding of EI and how it functions among counseling trainees could inform teaching, admissions, and curricular practices. Yet there is limited research exploring EI among counseling trainees. Therefore, we were interested in exploring the relationship between EI, cognitive and affective empathy, stress, distress, and the demographics in a sample of master's-level counseling trainees. The following exploratory research questions guided this investigation: (a) What are master's-level counseling trainees' levels of global trait EI, cognitive empathy, affective empathy, stress, and distress? (b) What is the relationship between master's-level counseling trainees' levels of global trait EI, cognitive empathy, affective empathy, stress, distress and their demographic characteristics? and (c) What is the relationship among master's-level counseling trainees' global trait EI, cognitive empathy, affective empathy, stress, and distress?

\section{Method}

\section{Participants and Procedure}

Our institutional review boards approved this multisite investigation. We used a convenience sample of graduate counseling trainees in programs accredited by the Council for Accreditation of Counseling and Related Educational Programs at four universities in three separate states, with all programs located in the southeastern region of the United States. Three of the four data collection sites had tracks in clinical mental health counseling, school counseling, student affairs and college counseling, or marriage and family counseling. One site was accredited by both CACREP and the American Association of Pastoral Counselors, and within this study, we classified this site as a pastoral counseling program. We pursued this set of counseling programs to increase the diversity of trainee specialty focus. We used a convenience sample because it provided the most effective and efficient method of recruiting a large number of participants. We contacted the counselor education program coordinators or department chairs and 
requested access to faculty members. Faculty members were subsequently asked permission to survey students during their respective classes.

The survey administrations were face-to-face and followed the same procedures for each site. During the survey administrations, we passed out selfsealing manila envelopes that included the consent form, survey instruments, and the demographics questionnaire. If students wished to participate, they completed the research materials and returned them in a sealed envelope. If students decided to forgo participation, they returned the sealed envelope with blank documents, which allowed for the calculation of a response rate. We determined a minimum sample size for this study to be 67 , based on two independent variables at a power of .80 and an anticipated effect size of .15 $(\alpha=.05)$ using an a priori sample size calculator (J. Cohen, Cohen, West, Aiken, 2003; Soper, 2016).

In the end, 307 master's-level counseling trainees from four CACREPaccredited counseling programs were invited to participate, with 305 individuals completing instrument packets (99\% response rate). Two hundred and forty-nine $(81.6 \%)$ participants identified as female and $55(18.0 \%)$ as male; one $(0.3 \%)$ participant reported other. The participants' average age was 30.73 years $(S D=10.83)$. Two hundred and thirteen participants $(69.8 \%)$ identified as White, $56(18.4 \%)$ identified as Black or African American, 19 (6.2\%) identified as Hispanic or Latino, eight (2.6\%) identified as other, five $(1.6 \%)$ identified as multiracial, and three $(1.0 \%)$ identified as Asian; one participant $(0.3 \%)$ did not report his or her race/ethnicity. On average, participants had completed $19.84(S D=17.16)$ credit hours of their graduate-level course work. CACREP-accredited programs require at least 48 hours of course work; therefore, our sample was representative of students in the first half of their degree of study. One hundred and eleven $(36.4 \%)$ respondents planned careers in the mental health counseling field, $86(28.2 \%)$ in school counseling, $68(22.3 \%)$ in pastoral counseling, 22 $(7.2 \%)$ in marriage and family therapy, $12(3.9 \%)$ in substance abuse, and six $(2.0 \%)$ in college counseling and student affairs. (Percentages in this section may not total 100 because of rounding.)

\section{Instruments}

We used three instruments to examine the research questions: (a) Perceived Stress Scale (PSS; S. Cohen, Kamarck, \& Mermelstein, 1983), (b) Interpersonal Reactivity Index (IRI; Davis, 1980), and (c) Trait Emotional Intelligence Questionnaire-Short Form (TEIQue-SF; Cooper \& Petrides, 2010). In addition, we used a demographics form to gather information about the participants.

PSS. The PSS was used to measure participants' level of stress. The PSS is a 10-item self-report scale that assesses "how unpredictable, uncontrollable, and overloaded respondents find their lives" (Cohen \& Williamson, 1988, p. 34). Respondents select the frequency for which they experienced a stressrelated phenomenon on a corresponding Likert-type scale ranging from 0 (never) to 4 (very often). Total scores are calculated by summing all of the 
items, with consideration given to reverse-scored items. Sample items include "In the last month, how often have you been upset because of something that happened unexpectedly?" "In the last month, how often have you felt nervous and 'stressed'?" and "In the last month, how often have you felt that you were on top of things?" (The last question was reverse coded.) The PSS has produced good internal consistency, with Cronbach's alphas ranging from .84 to .91 (Chao, 2011; S. Cohen et al., 1983). In this study, the internal consistency coefficient of the PSS was good, with a Cronbach's alpha of .88 (Streiner, 2003).

IRI. The IRI is a 28-item measure that includes seven items for each of the subscales. The IRI subscales include (a) Perspective Taking (PT), (b) Empathetic Concern (EC), (c) Fantasy, and (d) Personal Distress (PD). In our investigation, we used three of the four subscales (i.e., PT, EC, and PD) on the IRI to examine participants' cognitive empathy, affective empathy, and personal distress. Participants rate each item on a 5-point Likert-type scale ranging from 0 (does not describe me well) to 4 (describes me very well). Subscale total scores are calculated by summing all of the items for each subscale, with consideration given to reverse-scored items. The PT subscale measures cognitive empathy, which is defined as the ability of an individual to take the psychological perspective of others (Davis, 1980). The EC subscale measures affective empathy and one's ability to feel concern for others who are facing challenging situations (Davis, 1980). The use of these two subscales is a common approach to measure empathy in the counseling research literature (e.g., DePue \& Lambie, 2014; Fulton \& Cashwell, 2015). The PD subscale measures the feelings of anxiety and uneasiness associated with hearing about the negative or tense experience another person undergoes (Davis, 1980). The Fantasy subscale measures the tendency of respondents to place themselves within the feelings and experience of fictional characters (Davis, 1980); however, we did not include this subscale in the data analysis for this study because it did not directly address the research questions explored. Previous studies have found the PT, EC, and PD subscales to be reliable, with internal consistency coefficients ranging from .75 to .99 , from .70 to .79 , and from .75 to .78, respectively (Davis, 1980; DePue \& Lambie, 2014; Fulton \& Cashwell, 2015). The internal consistency coefficients of the IRI subscales in this study were acceptable, with Cronbach's alphas of .73 (PT), .72 (EC), and .77 (PD; Streiner, 2003).

TEIQue-SF. We used the TEIQue-SF to assess respondents' EI. The TEIQue$\mathrm{SF}$ is a 30 -item self-report scale that measures global trait EI and is based on the long form Trait Emotional Intelligence Questionnaire (TEIQue; Petrides \& Furnham, 2003). The TEIQue-SF includes two items from the 15 subscales of the TEIQue. Twenty-six of the 30 items form four subscales that include Well-Being (six items), Self-Control (six items), Emotionality (eight items), and Sociability (six items), whereas the remaining four items represent stand-alone facets of global trait EI. Participants rate their level of agreement with item statements on a Likert scale ranging from 1 (completely disagree) to 7 (completely agree). A total score for global trait EI is calculated 
by summing all of the items, with consideration given to reverse-scored items. In previous research, the TEIQue-SF global trait score had produced good internal consistency, with Cronbach's alphas ranging from .87 to .89 (Siegling, Vesely, Petrides, \& Saklofske, 2015). The internal consistency coefficient of the TEIQue-SF in this study was good, with a Cronbach's alpha of .86 (Streiner, 2003).

\section{Data Cleaning and Screening}

Of the 305 completed packets, there were no instruments with missing data. Before conducting the analyses, we screened the data for outliers. An examination of the data points that were \pm 3 standard deviations from the mean identified five cases of extreme outliers (Osborne, 2012). To accommodate these outliers, we calculated Winsorized means to replace the outliers based on the adjacent data points (Barnett \& Lewis, 1994; Osborne \& Overbay, 2004). Then, we analyzed the fit between the distribution of the variance and the assumptions for the statistical analysis used (e.g., normality, homogeneity of variance, linearity, multicollinearity; Hair, Black, Babin, Anderson, \& Tatham, 2010; Tabachnik \& Fidell, 2013). We found no violations of the statistical assumptions for the primary variables. However, participants' age was not normally distributed but instead produced a positively skewed distribution; therefore, any analysis involving participants' age used a nonparametric analysis.

\section{Data Analysis}

We chose a cross-sectional, correlational research design to examine the relationship between the variables in their natural state without manipulation (Gall, Gall, \& Borg, 2007). We entered and analyzed data using SPSS (Version 20) at the conclusion of the collection procedures. We conducted several analyses to examine the relationship between the variables and participants' demographic characteristics, including Pearson product-moment correlations, independent-samples $t$ tests, and a one-way between-groups analysis of variance (ANOVA). In addition, we applied nonparametric statistical analyses (e.g., Spearman's rank correlations) to procedures that involved participants' age because age violated the assumption of a normal distribution. Furthermore, we used several standard multiple linear regression analyses, including the interpretation of beta and structure coefficients. We calculated structure coefficients in addition to beta weights because they aid in interpreting the strength of independent (predictor) variables when the independent variables are highly correlated (Courville \& Thompson, 2001; Thompson \& Borrello, 1985).

\section{Results}

In the following sections, we discuss the results of the data analysis. We begin by describing our initial findings on EI, empathy, stress, and distress; the means, standard deviations, and correlations for these variables are presented in Table 1. Subsequently, we explore the relationships between these constructs. 
TABLE 1

Means, Standard Deviations, and

Correlations for the Study Variables

\begin{tabular}{|c|c|c|c|c|c|c|c|c|c|}
\hline Variable & 1 & 2 & 3 & 4 & 5 & 6 & 7 & $M$ & $S D$ \\
\hline 1. Emotional intelligence & - & & & & & & & 5.40 & 0.58 \\
\hline & $.35^{\star \star \star}$ & - & & & & & & & 0.52 \\
\hline athy & $.47^{\star \star \star}$ & $.42^{\star \star \star}$ & - & & & & & 2. & 0.57 \\
\hline 4. S & $-.54^{\star \star \star}$ & -.08 & $-.19^{\star \star}$ & - & & & & & 0.61 \\
\hline 5. Distress & $-.48^{\star \star \star}$ & -.06 & $-.18^{\star \star}$ & $.31^{\star \star *}$ & - & & & 1.42 & 0.67 \\
\hline 6. Age & $.15^{\star \star}$ & $.16^{\star \star}$ & .06 & $-.16^{\star \star}$ & $-.27^{\star \star \star}$ & - & & 30.73 & 10.83 \\
\hline 7. Graduate work & -.02 & .01 & .05 & .02 & -.03 & $.14^{*}$ & - & 19.84 & 17.16 \\
\hline
\end{tabular}

Note. $N=305$. Age uses Spearman's rank correlation coefficient; all other variables use the Pearson product-moment correlation coefficient. Graduate work = hours of completed graduate work.

${ }^{*} p<.05 .{ }^{* *} p<.01 .{ }^{* *} p<.001$.

\section{El}

We measured counseling trainees' level of global trait EI using the TEIQueSF. The mean score on the TEIQue-SF was $5.40(S D=0.58)$. Participants' TEIQue-SF scores did not have a statistically significant relationship with their hours of completed graduate work. However, participants' TEIQueSF scores did have a small, positive correlation with age $(\rho=.15, p<.01)$, with higher age being associated with higher EI. There was no statistically significant difference in TEIQue-SF scores based on participants' specialization, ethnicity, or gender.

\section{Empathy}

We measured counseling trainees' level of empathy using the PT and EC subscales on the IRI. We used the PT subscale to measure cognitive empathy and the EC subscale to measure affective empathy. The mean score on the PT subscale was $2.90(S D=0.57)$, and the mean score on the EC subscale was $3.21(S D=0.52)$. The PT and EC scores did not have a statistically significant relationship with participants' hours of completed graduate work. Also, PT scores did not have a statistically significant relationship with age, whereas EC scores were found to have a small positive correlation with age $(\rho=.16, p<.01)$. In addition, there was no statistically significant difference in PT and EC scores based on participants' specialization, ethnicity, or gender.

\section{Stress}

We measured counseling trainees' level of stress using the PSS. The mean score on the PSS was $1.52(S D=0.61)$. The PSS scores did not have a statistically significant relationship with participants' hours of completed graduate work. However, there was a small, negative correlation between stress and age $(\rho=-.16, p<.01)$, with higher age being associated with lower levels of stress. Furthermore, there was no statistically significant difference in PSS scores based on participants' specialization, ethnicity, or gender. 


\section{Distress}

We measured counseling trainees' level of distress using the PD scale on the IRI. The mean PD score was $1.42(S D=0.67)$. Participants' PD scores did not have a statistically significant relationship with their hours of completed graduate work. However, there was a moderate, negative correlation between distress and age $(\rho=-.27, p<.001)$, with higher age being associated with lower levels of distress. In addition, there was no statistically significant difference in PD scores based on participants' ethnicity.

An independent-samples $t$ test revealed a significant difference in PD scores for men $(M=1.17, S D=0.62)$ and women $(M=1.48, S D=0.67), t(302)=$ $3.05, p<.01$. The magnitude of the differences in the means (mean difference $=0.30,95 \%$ confidence interval $[0.11,0.50])$ was small $\left(\eta^{2}=.03\right)$. A one-way between-groups ANOVA resulted in a statistically significant difference in PD scores based on participants' identified discipline, $F(5,304)=$ $6.19, p<.001, \eta^{2}=.09$. A Tukey post hoc analysis revealed that the mean score for participants in the pastoral counseling discipline $(M=1.14, S D=$ 0.60 ) was significantly different from the mean scores of the participants in the school counseling $(M=1.67, S D=0.62)$ and mental health counseling disciplines $(M=1.43, S D=0.72)$, but no other statistically significant differences were present.

\section{Relationship Between Empathy and El}

We applied a standard multiple linear regression analysis to the outcome variable of global trait EI (scores on the TEIQue-SF) using the independent (predictor) variables of affective empathy and cognitive empathy (scores on the EC and PT subscales on the IRI, respectively; see Table 2). Overall, the linear composite of the independent variables (affective and cognitive empathy) predicted $25 \%\left(R^{2}=.25\right.$, adjusted $\left.R^{2}=.25\right)$ of the variance in global trait EI, $F(2,304)=50.83, p<.001$. The beta coefficients for both predictor variables were statistically significant. The beta weights indicated that there was a $.18(\beta=.18, p=.001)$ unit increase observable in the global trait EI scores for every increase in affective empathy score and that there was a $.40(\beta=.40, p<.001)$ unit increase observable in the global trait EI scores for every increase in cognitive empathy score. The structure coefficients (Courville \& Thompson, 2001; Thompson \& Borrello, 1985) supported the

\section{TABLE 2}

\section{Regression Results for Empathy, Stress, and Distress on Emotional Intelligence}

\begin{tabular}{|c|c|c|c|c|c|c|c|}
\hline Predictor Variable & $B$ & SE B & $\beta$ & $r_{\mathrm{s}}$ & $t$ & $F$ & $R^{2}$ \\
\hline Cognitive empathy & .40 & .06 & .40 & .94 & $7.29^{\star \star \star}$ & $50.83^{* * *}$ & .25 \\
\hline Affective empathy & .20 & .06 & .18 & .69 & $3.29^{\star \star \star}$ & $50.83^{\star * *}$ & .25 \\
\hline Stress & -.40 & .04 & -.43 & -.85 & $-9.05^{\star \star \star}$ & $99.36^{\star \star \star}$ & .40 \\
\hline Distress & -.30 & .04 & -.35 & -.76 & $-7.43^{\star \star \star}$ & $99.36^{\star \star *}$ & .40 \\
\hline
\end{tabular}

Note. $N=305 . r_{\mathrm{s}}=$ structure coefficient.

${ }^{* * *} p<.001$. 
results that cognitive empathy was a stronger predictor of global trait EI $(r$ s $=.94)$ compared with affective empathy $\left(r_{\mathrm{s}}=.69\right)$.

We further explored the relationship between global trait EI, affective empathy, and cognitive empathy using Pearson product-moment correlations. A positive relationship was identified between global trait EI and affective empathy $(r=.35, p<.001 ; 12 \%$ of the variance explained). Furthermore, a positive relationship was identified between global trait EI and cognitive empathy ( $r=.47, p<.001 ; 22 \%$ of the variance explained). Therefore, counseling trainees who reported a higher level of EI also reported higher levels of cognitive and affective empathy.

\section{Relationship Between Stress, Distress, and EI}

We applied a standard multiple linear regression analysis to the outcome variable of global trait EI (scores on the TEIQue-SF) using the independent (predictor) variables of stress (scores on the PSS) and distress (scores on the PD subscale on the IRI; see Table 2). Overall, the linear composite of the independent variables (stress and distress) predicted $40 \%\left(R^{2}=.40\right.$, adjusted $\left.R^{2}=.39\right)$ of the variance in global trait EI, $F(2,304)=99.36, p<.001$. The beta coefficients for both predictor variables were statistically significant. The beta weights indicated that there was a .35 $(\beta=-.35, p=.001)$ unit decrease observable in the global trait EI scores for every increase in distress score and that there was a $.43(\beta=-.43, p<.001)$ unit decrease observable in the global trait EI scores for every increase in stress score. Furthermore, the structure coefficients supported the findings that stress was a stronger predictor of global trait EI $\left(r_{\mathrm{s}}=-.85\right)$ compared with distress $\left(r_{\mathrm{s}}=-.76\right)$.

We further explored the relationship between global trait EI, affective empathy, and cognitive empathy using Pearson product-moment correlations. A negative relationship was identified between global trait EI and stress $(r$ $=-.54, p<.001 ; 29 \%$ of the variance explained). Furthermore, a negative relationship was identified between global trait EI and distress $(r=-.48, p<$ $.001 ; 23 \%$ of the variance explained). Therefore, counseling trainees who reported a higher level of EI also reported lower levels of stress and distress.

\section{Discussion}

As previously noted, the empirical investigation of EI is rare in the counseling literature, yet EI may inform counselor educators' understanding of the development of their students and supervisees. The data from this study provide two findings that inform counselor education: (a) higher EI is related to higher counselor empathy and (b) higher EI is related to lower stress and distress.

We explored the relationship between four aspects of counselor identity and practice: EI, empathy, stress, and distress. The first two research questions investigated master's students' levels of EI, cognitive empathy, affective empathy, distress, and stress, as well as the relationship between those constructs and participants' demographic characteristics. These results suggest that age played a meaningful, albeit minor, role in the resulting associations. 
We found that EI and affective empathy were positively correlated (with a small effect size) with age, which suggests that increases in counseling trainees' age correspond to increases in EI and affective empathy, as measured by the TEIQue-SF and the EC subscales, respectively. Likewise, there was a small, negative correlation between age and stress, with higher age being associated with lower stress scores. The same was also true for distress: Students' age demonstrated a moderate correlation with lower scores on their perceived ability to handle hearing about the difficult experiences of others. Our findings suggest that as counselors increase in age, they are reportedly better apt to cope with hearing about difficult topics from clients without experiencing overwhelming emotions. Because counseling trainees likely encounter similar topics in their classroom experiences, one would expect that older participants are also less stressed by these topics during their training programs. As previous researchers have noted, stress can negatively influence counselor performance (Bowman et al., 1978; Friedlander et al., 1986; Stoltenberg \& McNeill, 2010; Young 2013), so taking into account student age may help counselor educators better anticipate and mitigate the role stress plays in counselor development.

There were also differences based on discipline (medium effect size), with pastoral counseling trainees reporting lower levels of distress in comparison with school counseling and mental health counseling trainees. Thus, it is possible that a program of study focusing on the spiritual and religious concerns that clients bring to counseling could attract students who themselves are reportedly more resilient in encountering difficult topics from clients or that spirituality or religion itself functions as a mediator or moderator variable influencing the counselors' ability to empathize. One final difference emerged in relation to gender, with men scoring slightly lower on distress compared with women. However, this difference could be a function of demand characteristics; that is, men could have responded to items on our measure of distress to align with traditional gender-role expectations (e.g., men handle difficult emotions without being negatively affected) or their idea of how a counselor should respond on the scale.

The third and final research question explored the relationship between EI, cognitive empathy, affective empathy, stress, and distress. Both predictors (affective and cognitive empathy) explained significant portions of variance in EI, with cognitive empathy emerging as a superior predictor overall. This partially stands to reason given the similarity between the two constructs. However, this finding provides further evidence that a significant relationship does exist between empathy and EI, which supports previous research (Bar-On, 1997; Goleman, 2005; Petrides \& Furnham, 2001, 2003).

Finally, both distress and stress accounted for significant variance in EI scores. In this case, the opposite type of relationship emerged: Higher scores of distress and stress were predictive of lower EI scores. These results suggest that counselors who more adeptly manage their own emotional state and read and appropriately respond to the emotional state of others will also be less distressed by clients' painful stories. Simultaneously, they may be less stressed 
and, therefore, less likely to experience the negative effects of chronic stress (i.e., burnout; Hayes \& Gelso, 2001; Stebnicki, 2007). The results of the first and second regression and correlation analyses underscore the assertions of Young (2013) that EI plays a significant role in empathic attunement and, by extension, the counselor's performance in therapeutic skills. Although researchers have claimed that stress will negatively influence empathic ability (Bowman \& Giesen, 1982), our findings suggest that it is equally important to take into account students' levels of EI when assessing their empathic aptitude. Because empathy is a primary factor in client change (Norcross, 2011), our findings indicate that counselor educators should focus on the EI their students possess. This would also mean that students' experiences of stress during their development would be quantitatively different depending on their levels of EI. Instead of assuming outright that stress in counselor development is a homogeneous process, our findings caution against any simplistic explanation of students' experience of burnout as a result of stress (e.g., counseling trainees will experience stress and will eventually burn out). On the contrary, it appears more important to recruit students with higher levels of EI and train students to increase their EI because they are more likely to be empathic and prevent those conditions that are associated with impaired practice.

\section{Implications for Counselor Education}

These findings demonstrate that EI has a significant relationship with constructs germane to counseling, such as empathy and stress management. Thus, the findings provide several implications for counselor education. The major finding that empathy is related to EI is especially salient for counselor educators. We used a multidimensional measure of empathy that allowed us to investigate what factors of empathy (i.e., cognitive or affective) related to EI. We found statistically significant relationships between EI and both affective and cognitive empathy, indicating that the EI of counselors does relate to multiple facets of empathy. Because we used a comprehensive measure of empathy and a large sample of student counselors, we believe that these findings provide a strong rationale for the inclusion of EI into the counselor curriculum. Counselor educators should find methods for addressing students' EI levels throughout the course of their programs. One approach would be to ensure that traditionally content-laden courses incorporate emotion-related topics in the curriculum and provide students an opportunity to process their emotional reactions to material. In addition, previous research has found mindfulness to be beneficial for increasing EI (Chu, 2010; Lomas, Edginton, Cartwright, \& Ridge, 2013; Perelman et al., 2012); thus, counselor educators and supervisors may consider incorporating mindfulness and other experiential activities into their classroom curricula. Finally, in light of these findings, counselor educators could use EI as a tool in the admissions process and as an assessment throughout their programs. Counselor educators could administer a validated EI scale to students during the admissions process or at an early point in the program and again before their clinical training to determine if their curricula are increasing student EI or if more pedagogical time should 
be spent on fostering EI in students. In addition, assessing student EI may prove beneficial in making admissions decisions. Because this research is still in its early stages, we do not recommend that EI be the sole measure used in the student admissions process, but it may be useful to supplement traditional admissions procedures by including some measure of EI during program orientation. For example, the Mayer-Salovey-Caruso Emotional Intelligence Test (Mayer, Salovey, Caruso, \& Sitarenios, 2003) and Workgroup Emotional Intelligence Profile (Jordan, Ashkanasy, Härtel, \& Hooper, 2002) may provide insight regarding applicants' EI.

\section{Limitations and Directions for Future Research}

There are limitations to these findings. First, the study is cross-sectional and not an experimental design; thus, we cannot suggest causation. It is important to see the relationships between the variables and to note the degree of contribution, but for us to imply any causal effect would necessitate further research. In addition, given our large sample size $(N=305)$ and the use of multiple sites for recruitment, we believe that our data provide a comprehensive examination of the constructs in question. However, it is difficult to know how generalizable these findings are without further research into other regions of the United States and around the world. Furthermore, $22.3 \%$ of the participants were in a CACREP-accredited counseling program that specialized in pastoral counseling. Little is known about the difference between students in CACREP-accredited pastoral counseling programs and those in traditional counseling programs, and it is possible that there is a qualitative difference between these two groups.

Despite these limitations and because of the statistical and practical significance of these findings, we believe that this exploratory study creates a foundation for future research. Future researchers should consider examining the effects of interventions that include EI in the counselor curriculum. Moreover, future research is needed to determine how students can develop EI in their counselor education programs (e.g., longitudinal study) and what factors influence the development of EI (e.g., accredited vs. nonaccredited programs). We also believe that future researchers should continue to explore how age and pastoral counseling training influence personal distress. Finally, future researchers should examine how strengthening students' EI could increase their effectiveness with clients and in the classroom.

\section{References}

Bakker, A. B., Van Der Zee, K. I., Lewig, K. A., \& Dollard, M. F. (2006). The relationship between the Big Five personality factors and burnout: A study among volunteer counselors. The Journal of Social Psychology, 146, 31-50. doi:10.3200/SOCP.146.1.31-50

Barnett, V., \& Lewis, T. (1994). Outliers in statistical data (Vol. 3). New York, NY: Wiley.

Bar-On, R. (1997). BarOn Emotional Quotient Inventory: Technical manual. Toronto, Ontario, Canada: Multi-Health Systems.

Bedwell, S. (2002). Emotional Judgment Inventory: Research manual. Champaign, IL: Institute for Personality and Ability Testing.

Bike, D. H., Norcross, J. C., \& Schatz, D. M. (2009). Processes and outcomes of psychotherapists' personal therapy: Replication and extension 20 years later. Psychotherapy: Theory, Research, Practice, Training, 46, 19-31. doi:10.1037/a0015139 
Bowman, J. T., \& Giesen, J. M. (1982). Predicting ratings of counselor trainee empathy with self-report anxiety measures and skin conductance. Counselor Education and Supervision, 22, 154-161. doi:10.1002/j.1556-6978.1982.tb01717.x

Bowman, J. T., Roberts, G. T., \& Giesen, J. M. (1978). Counselor trainee anxiety during the initial counseling interview. Journal of Counseling Psychology, 25, 137-143.

Chao, R. C.-L. (2011). Managing stress and maintaining well-being: Social support, problemfocused coping, and avoidant coping. Journal of Counseling Eं Development, 89, 338-348. doi:10.1002/j.1556-6678.2011.tb00098.x

Cherniss, C., \& Goleman, D. (2001). The emotionally intelligent workplace. San Francisco, CA: Jossey-Bass.

Chu, L.-C. (2010). The benefits of meditation vis-á-vis emotional intelligence, perceived stress, and negative mental health. Stress and Health, 26, 169-180. doi:10.1002/smi.1289

Cohen, J., Cohen, P., West, S. G., \& Aiken L. S. (2003). Applied multiple regression/correlation analysis for the behavioral sciences. Mahwah, NJ: Erlbaum.

Cohen, S., Kamarck, T., \& Mermelstein, R. (1983). A global measure of perceived stress. Journal of Health and Social Behavior, 24, 385-396. doi:10.2307/2136404

Cohen, S., \& Williamson, G. (1988). Perceived stress in a probability sample of the US. In S. Spacapam \& S. Oskamp (Eds.), The social psychology of health: Claremont symposium on applied social psychology (pp. 31-67). New York, NY: Sage.

Cooper, A., \& Petrides, K. V. (2010). A psychometric analysis of the Trait Emotional Intelligence Questionnaire-Short Form (TEIQue-SF) using item response theory. Journal of Personality Assessment, 92, 449-457. doi:10.1080/00223891.2010.497426

Courville, T., \& Thompson, B. (2001). Use of structure coefficients in published multiple regression articles: $\beta$ is not enough. Educational and Psychological Measurement, 61, 229-248.

Davis, M. H. (1980). A multidimensional approach to individual differences in empathy. JSAS Catalog of Selected Documents in Psychology, 10, 85.

DePue, M. K., \& Lambie, G. W. (2014). Impact of a university-based practicum experience on counseling students' levels of empathy and assessed counseling competencies. Counseling Outcome Research and Evaluation, 5, 89-101. doi:10.1177/2150137814548509

Duan, C., \& Hill, C. E. (1996). The current state of empathy research. Journal of Counseling Psychology, 43, 261-274. doi:10.1037/0022-0167.43.3.261

Easton, C., Martin, W. E., \& Wilson, S. (2008). Emotional intelligence and implications for counseling self-efficacy: Phase II. Counselor Education and Supervision, 47, 218-232. doi:10.1002/j.1556-6978.2008.tb00053.x

Elliott, R., Bohart, A. C., Watson, J. C., \& Greenberg, L. S. (2011). Empathy. Psychotherapy, 48, 43-49. doi:10.1037/a0022187

Friedlander, M. L., Keller, K. E., Peca-Baker, T. A., \& Olk, M. E. (1986). Effects of role conflict on counselor trainees' self-statements, anxiety level, and performance. Journal of Counseling Psychology, 33, 73-77. doi:10.1037/0022-0167.33.1.73

Fulton, C. L., \& Cashwell, C. S. (2015). Mindfulness-based awareness and compassion: Predictors of counselor empathy and anxiety. Counselor Education and Supervision, 54, 122-133. doi:10.1002/ceas.12009

Gall, M. D., Gall, J. P., \& Borg, W. R. (2007). Educational research: An introduction. Boston, MA: Pearson/Allyn \& Bacon.

Goleman, D. (2005). Emotional intelligence: Why it can matter more than IQ. London, England: Bloomsbury.

Gutierrez, D., Conley, A. H., \& Young, M. E. (2016). The effect of Jyoti meditation on student counselors' stress and emotional intelligence: A randomized controlled trial. Counselor Education and Supervision, 55, 109-121.

Gutierrez, D., \& Mullen, P. R. (2016). Emotional intelligence and the counselor: Examining the contribution of trait emotional intelligence to counselor burnout. Journal of Mental Health Counseling, 38, 187-200. doi:10.17744/mehc.38.3.01

Hair, J. F., Black, W. C., Babin, B. J., Anderson, R. E., \& Tatham, R. L. (2010). Multivariate data analysis (Vol. 7). Upper Saddle River, NJ: Pearson Prentice Hall.

Hayes, J. A., \& Gelso, C. J. (2001). Clinical implications of research on countertransference: Science informing practice. Journal of Clinical Psychology, 57, 1041-1051. doi:10.1002/jclp.1072

Ivey, A., Ivey, M., \& Zalaquett, C. (2013). Intentional interviewing and counseling: Facilitating client development in a multicultural society. Belmont, CA: Cengage Learning.

Jordan, P. J., Ashkanasy, N. M., Härtel, C. E. J., \& Hooper, G. S. (2002). Workgroup emotional intelligence: Scale development and relationship to team process effectiveness and goal focus. Human Resource Management Review, 12, 195-214. 
Kaplan, D. M., Tarvydas, V. M., \& Gladding, S. T. (2014). 20/20: A vision for the future of counseling: The new consensus definition of counseling. Journal of Counseling E Development, 92, 366-372. doi:10.1002/j.1556-6676.2014.00164.x

Lee, S. M., Baker, C. R., Cho, S. H., Heckathorn, D. E., Holland, M. W., Newgent, R. A., . . . $\mathrm{Yu}$, K. (2007). Development and initial psychometrics of the Counselor Burnout Inventory. Measurement and Evaluation in Counseling and Development, 40, 142-154.

Lomas, T., Edginton, T., Cartwright, T., \& Ridge, D. (2013). Men developing emotional intelligence through meditation? Integrating narrative, cognitive, and electroencephalography (EEG) evidence. Psychology of Men E Masculinity, 14, 1-10.

Martin, W. E., Easton, C., Wilson, S., Takemoto, M., \& Sullivan, S. (2004). Salience of emotional intelligence as a core characteristic of being a counselor. Counselor Education and Supervision, 44, 17-30. doi:10.1002/j.1556-6978.2004.tb01857.x

Mayer, J. D., Salovey, P., \& Caruso, D. R. (2008). Emotional intelligence: New ability or eclectic traits? American Psychologist, 63, 503-517. doi:10.1037/0003-066X.63.6.503

Mayer, J. D., Salovey, P., Caruso, D. R., \& Sitarenios, G. (2003). Measuring emotional intelligence with the MSCEIT V2.0. Emotion, 3, 97-105. doi:10.1037/1528-3542.3.1.97

Norcross, J. C. (Ed.) (2011). Psychotherapy relationships that work: Evidence-based responsiveness (2nd ed.). New York, NY: Oxford University Press.

Norcross, J. C., \& Wampold, B. E. (2011). Evidence-based therapy relationships: Research conclusion and clinical practices. Psychotherapy, 48, 98-102. doi:10.1037/a0022161

Osborne, J. W. (2012). Best practices in data cleaning: A complete guide to everything you need to do before and after collecting your data. Thousand Oaks, CA: Sage.

Osborne, J. W., \& Overbay, A. (2004). The power of outliers (and why researchers should always check for them). Practical Assessment, Research Eं Evaluation, 9, 1-12.

Perelman, A. M., Miller, S. L., Clements, C. B., Rodriguez, A., Allen, K., \& Cavanaugh, R. (2012). Meditation in a Deep South prison: A longitudinal study of the effects of Vipassana. Journal of Offender Rehabilitation, 51, 176-198. doi:10.1080/10509674.2011.632814

Petrides, K. V., \& Furnham, A. (2001). Trait emotional intelligence: Psychometric investigation with reference to established trait taxonomies. European Journal of Personality, 15, 425-448. doi:10.1002/per.416

Petrides, K. V., \& Furnham, A. (2003). Trait emotional intelligence: Behavioural validation in two studies of emotion recognition and reactivity to mood induction. European Journal of Personality, 17, 39-57. doi:10.1002/per.466

Roach, L. F., \& Young, M. E. (2007). Do counselor education programs promote wellness in their students? Counselor Education and Supervision, 47, 29-45. doi:10.1002/j.1556-6978.2007. tb00036.x

Rogers, C. R. (1957). The necessary and sufficient conditions of therapeutic personality change. Journal of Counseling Psychology, 21, 95-103. doi:10.1037/h0045357

Salovey, P., \& Mayer, J. D. (1990). Emotional intelligence. Imagination, Cognition, and Personality, 9, 185-211.

Siegling, A. B., Vesely, A. K., Petrides, K. V., \& Saklofske, D. H. (2015). Incremental validity of the Trait Emotional Intelligence Questionnaire-Short Form (TEIQue-SF). Journal of Personality Assessment, 98, 525-535. doi:10.1080/00223891.2015.1013219

Skovholt, T. M., Grier, T. L., \& Hanson, M. R. (2001). Career counseling for longevity: Self-care and burnout prevention strategies for counselor resilience. Journal of Career Development, 27, 167-176. doi:10.1177/089484530102700303

Soper, D. S. (2016). A-priori sample size calculator for multiple regression [Computer software]. Retrieved from http://www.danielsoper.com/statcalc/calculator.aspx?id=1

Stebnicki, M. A. (2007). Empathy fatigue: Helping the mind, body, and spirit of professional counselors. American Journal of Psychiatric Rehabilitation, 10, 317-338. doi:10.1080/15487760701680570

Stoltenberg, C. D., \& McNeill, B. W. (2010). IDM supervision: An integrative developmental model for supervising counselors and therapists (3rd ed.). New York, NY: Routledge.

Streiner, D. L. (2003). Starting at the beginning: An introduction to coefficient alpha and internal consistency. Journal of Personality Assessment, 80, 99-103. doi:10.1207/s15327752jpa8001_18

Tabachnik, B. G., \& Fidell, L. S., (2013). Using multivariate statistics (6th ed.) Boston, MA: Pearson.

Thompson, B., \& Borrello, G. M. (1985). The importance of structure coefficients in regression research. Educational and Psychological Measurement, 45, 203-209.

Young, M. E. (2013). Learning the art of helping: Building blocks and techniques. Upper Saddle River, NJ: Pearson.

Young, M. E., \& Lambie, G. W. (2007). Wellness in school and mental health systems: Organizational influences. The Journal of Humanistic Counseling, 46, 98-113. doi:10.1002/j.2161-1939.2007. tb00028.x 